\title{
Erratum to: Closed Die Deformation Behavior of Cylindrical Iron-Alumina Metal Matrix Composites During Cold Sinter Forging
}

\author{
Undeti Jacob Prasanna Kumar ${ }^{1} \cdot$ Pallav Gupta $^{2,3} \cdot$ Arun Kant Jha $^{1} \cdot$ Devendra Kumar $^{2}$
}

Published online: 7 January 2016

(C) The Institution of Engineers (India) 2016

\section{Erratum to: J Inst Eng India Ser D \\ DOI 10.1007/s40033-015-0089-1}

Under the subheading 'Preparation of Composite Samples', at line no. 3, powder to ball ratio ' $2: 1$ ' was wrongly printed in the original publication of this article. The correct powder to ball ratio should be ' $1: 2$ '.

The online version of the original article can be found under doi:10.1007/s40033-015-0089-1.

Pallav Gupta

pallav.gupta.cer09@iitbhu.ac.in

1 Department of Mechanical Engineering, Indian Institute of Technology (Banaras Hindu University), Varanasi 221005, India

2 Department of Ceramic Engineering, Indian Institute of Technology (Banaras Hindu University), Varanasi 221005, India

3 Department of Mechanical and Automation Engineering, A.S.E.T., Amity University, Noida 201313, India 